\title{
Gestation length in farmed reindeer
}

\author{
MP Shipka ${ }^{1,2}$ and JE Rowell ${ }^{1}$ \\ 'Department of High Latitude Agriculture, School of Natural Resources and Agricultural Sciences, \\ University of Alaska Fairbanks, Fairbanks, Alaska; 'Center of Reproductive Biology, Washington State \\ University, Pullman, Washington
}

\begin{abstract}
Reindeer (Rangifer tarandus tarundus) are the only cervids indigenous to the arctic environment. In Alaska, reindeer are a recognized agricultural species and an economic mainstay for many native populations. Traditionally raised in extensive free-ranging systems, a recent trend toward intensive farming requires a more in-depth knowledge of reproductive management. Reported gestation length in reindeer varies, ranging from 198 to $229 \mathrm{~d}$ in studies performed at the University of Alaska Fairbanks. A switchback study that manipulated only breeding date demonstrated a mean increase in gestation length of $8.5 \mathrm{~d}$ among females bred early in the season. The negative correlation between conception date and gestation length is consistent with reindeer research at other locations and reports of variable gestation length in a growing number of domestic and nondomestic species. This paper reviews the phenomenon in reindeer and discusses some of the factors known to affect gestation length as well as possible areas for future research.
\end{abstract}

\section{Introduction}

Reindeer and caribou (Rangifer tarandus) are the only cervids indigenous to the arctic environment. With a circumpolar range extending from $45^{\circ}$ to $80^{\circ} \mathrm{N}$ (Leader-Williams 1988) these animals have adapted to extremes in light, temperature, and nutrient availability and exhibit a number of characteristics that sets them apart from other deer species. Notably, they are the only deer in which both the male and female grow antlers; their highly gregarious nature contributes to the formation of massive herds that migrate greater distances in the spring and fall than any other deer; and they have been subjected to widespread domestication (Goss 1983). Caribou and reindeer are considered members of the same species even though they exhibit morphological and behavioral differences. Reindeer are considered the longest domesticated cervid, with a history of domestication going back thousands of years (Diamond 1999). It was because of their predisposition to agricultural practices that reindeer from Siberia were introduced to Alaska slightly more than 100 years ago. Over the ensuing century reindeer producers maintained their herds under free-range conditions utilizing grazing allotments of more than 400,000 hectares per herd. Such a system of extensive ranching was very successful and well suited to the northern ecosystem.

Intensive farming of reindeer, using traditional agricultural practices, is relatively new in Alaska and currently represents only a small fraction of the state's reindeer industry. However, this approach to reindeer farming occurs in at least 17 of the 48 contiguous states. The University of Alaska Fairbanks (UAF, $65^{\circ} \mathrm{N}$ latitude) has established a program in Reindeer Reproductive Biology to support this emerging industry. 


\section{Reindeer reproductive biology}

The initial goal of the program was to document the basic reproductive biology of reindeer and to provide a better understanding of the endocrinology of the estrous cycle and pregnancy in farmed Alaskan reindeer. Reindeer are similar to other cervids and domestic livestock in general. They have a mean estrous cycle length of $24 \pm 1 \mathrm{~d}$ (range 18-29 d) (Shipka et al. 2007a). Reindeer females, under good husbandry conditions, will continue to cycle over the winter into March and April, (Bubenik et al. 1997, Blake et al. 2007, Shipka et al. 2007a). The endocrinology of pregnancy is also unremarkable and characteristic of a species dependent on luteal progesterone throughout gestation (Blake et al. 2007, Shipka et al. 2007a). Although the corpus luteum (CL) of pregnancy decreases in weight over the course of gestation, a functional CL is still present as late as 5.5 months (Roine 1974) and remains an important source of progesterone throughout gestation (Flood et al. 2005). Earlier studies in reindeer reproduction reported gestation lengths ranging from 208-240 d (McEwan \& Whitehead 1972, Dott \& Utsi 1973, Roine 1974, Bergerud 1975, Blom et al. 1983, Leader-Williams 1988, Reimers 2002), collectively providing a range in gestation length equivalent to almost two estrous cycles. In one study at UAF, the mean gestation length for 10 yearling females was $211 \pm 2,2 \mathrm{~d}$ but the range was 198 to $221 \mathrm{~d}$ (Shipka et al. 2007a) while a contemporary study of 13 multiparous reindeer provided a mean gestation length of $216 \mathrm{~d}$ with a range of 212 to $220 \mathrm{~d}$ (Ropstad et al. 2005). The wide range in gestation length has generally been accepted within the context of how the data were collected: field observations of free-ranging animals compared to reindeer maintained in fenced settings under very different management regimens at very different latitudes. In addition, across the aforementioned studies, the means of establishing the time of breeding were equally variable and sample sizes generally small.

In an early study at UAF, 14 female reindeer were divided into 2 groups that remained well separated from any bulls. One group was introduced to the bull on Aug 23 while the other group was introduced to the bull on Sept 25. Although the study was designed to investigate the seasonal onset of ovarian activity, progesterone profiles established the time of breeding in 8 females and produced a variable gestation length ranging from $203-229 \mathrm{~d}$. Breeding dates were spread over 26 days (Aug 31 - Sept 25) yet calving occurred over 7 days and there was a significant $(P<0.001)$ negative correlation between conception date and gestation length (Shipka et al. 2002). A retrospective examination of records from two reindeer herds at UAF where breeding dates (confirmed by systemic progesterone concentrations) and calving dates were known $(n=39)$ further strengthened this relationship. Females bred early in the season had a longer gestation than females bred later in the season (Shipka \& Rowell 2006). The hypothesis that manipulating breeding date can alter gestation length was tested using a switchback design and, again, produced a significant $(P<0.001)$ negative relationship between conception date and gestation length (Rowell \& Shipka 2009). The model generated by the switchback study has good predictive ability for female reindeer in good condition mated between late August and early October. Late bred animals consistently shorten gestation by 8-10 d. Despite small sample sizes, the results are strengthened by the documentation of a similar, highly significant, negative correlation between conception date and gestation length in Finnish reindeer (Ropstad et al. 2005, Holand et al. 2006, Mysterud et al. 2009) while anecdotal observations of this association in reindeer go back over 70 years (Schmit 1936, cited in Roine 1974). Across all these studies is the remarkably consistent, highly significant negative relationship between gestation length and breeding date.

Variable gestation length is not a unique observation. In the wild ruminant literature Berger (1992) introduced the concept of gestation plasticity in well conditioned bison and stressed the positive effect this had on maintaining calving synchrony. Recent documentation of a negative 
relationship between gestation length and conception date has been reported in a number of other species, most notably red deer (Asher 2006, Scott et al. 2008), Iberian red deer (Garcia et al. 2006), pronghorn antelope and bighorn sheep (Byers \& Hogg 1995), Alaskan moose (Schwartz \& Hundertmark 1993), alpacas (Davis et al. 1997), and dromedary camels (Elias et al. 1991). Although less apparent, the phenomenon has also been documented in domestic species. Howell and Rollins (1951) found season of breeding to be the single most important source of variation in gestation length of mares, independent of level of nutrition, with breeding in Sept - Nov producing the shortest gestätion lengths. Even among non-seasonally breeding dairy cattle, analysis of data from 11 million parturitions found a moderate effect of month of conception on gestation length, with October conceptions producing a gestation length $2 \mathrm{~d}$ shorter than conceptions in January and February (Norman et al. 2009).

\section{Factors affecting gestation length}

Gestation length, defined as the period of time from conception to parturition, has historically been recognized as a species-specific, genetically determined event. However, it has also been equally recognized that gestation length can be modified by a number of factors such as

i. fetal influences (fetal genetics, fetal sex, pituitary/adrenal axis)

ii. maternal conditions (age, body size, and condition)

iii. environment (season, temperature, and nutrition).

Species and breed differences in gestation length have been well documented in domestic animals (sheep, goats, horses, and cattle) and between the various cervid species. Because of highly variable gestation lengths among cervid hybrids, Asher (2007) suggested that species specific gestation length is likely governed by relatively few genes. Red deer carrying crossbred calves (wapiti $X$ red deer) experience a $2.5 \%$ increase in mean gestation length (Moore \& Littlejohn 1989), Although caribou and reindeer are considered the same species they differ in seasonal timing of reproductive events, with reindeer initiating estrous cycles 2-6 wk earlier than caribou even when both are raised under identical conditions (Leader-Williams 1988, Rowell \& Shipka 2009). Information on hybrid gestation length is not available, however, reported mean gestation lengths of 216.7 (range 206-231) for captive and 227 (range 219-238) for wild caribou (McEwan \& Whitehead 1972) are consistent with gestation lengths in reindeer (Shipka et al. 2007a). Hybridization between reindeer and caribou has occurred deliberately in an effort to increase carcass weight and may also occur where the ranges of the two subspecies overlap (Klein 1980), though gene flow between reindeer and caribou has been limited (Cronin et al. 2003). In our studies on gestation length the animals were all reindeer from the same genetic stock and thus genetics cannot account for the variable gestation length produced by manipulating breeding date.

Fetal influence through sex differences has been documented for a number of cervids including reindeer, with male reindeer calves reported to have slightly longer gestations ( $3-5 \mathrm{~d}$ ) (Roine 1974, Mysterud et al. 2009) and greater birth weights than females calves (Eloranta \& Nieminen 1986, Blake et al. 1998, Holand et al. 2006). Not all studies document a difference between male and female birth weight (Eloranta \& Nieminen 1988). In the switchback study there was no difference in birth weight between male and female calves, although there was a tendency for birth weight of males to increase with gestation length. This relationship was not evident for females and the sex of the calf was independent of gestation length (Rowell \& Shipka 2009). In both years of the switchback study the same sire was used to reduce any 
impact of the sire (through fetal genetics) on gestation length. Among red deer, no effect of calf sire was identified in a study of conception date and gestation length (Scott et al. 2008).

Age of the female at breeding can also affect gestation length. Maternal age and body weight are closely correlated; yearlings and primaparous reindeer are lighter, tend to breed later in the season, and have lighter offspring (Rognmo et al. 1983, Skogland, 1984, Eloranta \& Nieminen 1988, Lenvik et al. 1988, Ronnegard et al. 2002, Reimers 2002). Mysterud et al. (2009) documented increasing gestation length with maternal age. This was partly due to the fact that older, heavier females bred earlier in the season and, thus, had longer gestation lengths. In the switchback study the sample size was too small to examine the effects of age although there was a tendency for older females to have longer gestation lengths. Nonetheless, they still exhibited an 8-10 d difference between early and late conceptions (Rowell \& Shipka 2009).

Of the environmental impacts that can affect gestating females, the greatest body of information in semi domestic reindeer has examined the role of nutrition (reflected in maternal live weight and body condition) on gestation length, calf birth weight, and calf survival. It has been recognized for a long time that gestation length is extended in severely undernourished females (Bergerud 1975, Skogland 1984, Skogland 1990, Flydal \& Reimers 2002) and the incidence of stillbirths increased when pregnancy occurred in females on a low plane of nutrition (Tveraa et al. 2003). The correlation between calf birth weight and survival is the same in reindeer as it is in many temperate region ungulates, low birth weight and late born calves experience higher mortality rates than do calves $\geq$ mean birth weight, born during the primary calving pulse (Bergerud 1975, Rognmo et al. 1983, Skogland 1984, Tveraa et al. 2003, Fauchald et al. 2004). Birth weight of calves is significantly correlated with dam body weight just prior to calving (Rognmo et al. 1983, Ronnegard et al. 2002, Tveraa et al. 2003). In a study of fetal growth characteristics among reindeer in Norway, fetal growth was reduced by $42 \%$ in females on poor quality ranges (Flydal \& Reimers 2002, Reimers 2002). Fetal growth is apparently independent of female body condition for approximately the first two thirds of pregnancy, becoming susceptible to female condition only during the last third of gestation (Flydal \& Reimers 2002). Among red deer, experimentally restricting food intake during the last third of pregnancy extended mean gestation length ( $8 \mathrm{~d}$ ) and resulted in calves with the same birth weight as controls (Asher et al. 2005a). Conversely, when red deer were gestating hybrid calves (wapiti $X$ red deer) dietary restriction resulted in lighter birth weight calves but no significant difference in gestation length, leading the authors to suggest that fetal genotype overrode mechanisms for extending gestation length (Asher et al. 2005b). Among reindeer, feed restriction during the last 120 days of pregnancy extended gestation by 13 days in the feed restricted group (lichen diet) but also reduced calf birth weight by $36.5 \%$ with 2 neonatal deaths (Fauchald et al. 2004). The impact of nutrition on gestation length in cervids has produced variable results making it difficult to extrapolate beyond the restrictions imposed by individual studies.

Seasonal fluctuations in weight and fat reserves are a typical feature of ungulates in temperate zones and have been well described in reindeer (characterized by increasing weight gain peaking in late summer followed by a gradual weight decrease that reaches a nadir around the time of parturition and initiation of lactation) (Leader-Williams 1988). Captive, well fed reindeer maintain a less dramatic but similar cyclic pattern of growth and will voluntarily reduce food intake over the winter, regardless of available forage. In the switchback study the reindeer were fed ad libitum, and while body weight fluctuated throughout the winter, they all followed the same relative pattern of body weight change over the course of pregnancy with no significant differences in weight loss identified among animals across the two year study. Reindeer in suboptimal body condition are quite capable of taking advantage of available food and gaining weight during winter months (Shipka et al. 2007a). Pregnant females provided ad 
libitum feed in late pregnancy gained $18 \%$ of body weight in one study (Sakkinen et al. 1999) and $12 \%$ of initial body weight in another (Fauchald et al. 2004). Given this information, it is important to realize that the variable gestation length identified in the switchback study cannot be linked to a late winter nutritional deficit. The females in that study did not lose appreciable weight during the last trimester, always had access to ad libitum feed, and, with the exception of the six wk that encompassed the two harem periods, they were managed as a single group throughout gestation and calving. The only manipulation was conception date.

Other than nutrition, relatively little is known about environmental impacts on gestation. Severe winter weather has been implicated in prolonging gestation in dall's sheep (Rachlow \& Bowyer 1991). Alternatively, parturition and calving synchrony in Alaskan moose were not correlated with predation, snow depth or plant phenology (Bowyer et al. 1998). Evidence for direct effects of proximate environmental conditions on gestation length is inconsistent and difficult to demonstrate.

All of the above variables are known to affect gestation length, and all of them interact at different levels in reindeer populations. Yet none adequately explains the phenomenon of variable gestation length identified in captive reindeer here in Alaska or in the Scandinavian studies. Reindeer bred late in the season shorten gestation by $8.5 \mathrm{~d}$ (Rowell \& Shipka 2009) or $10 \mathrm{~d}$ (Holand et al. 2006) A similar interval was identified in lberian red deer (Garcia et al. 2006) and in red deer in New Zealand (Scott et al. 2008) While variable gestation enhances calving synchrony it doesn't necessarily produce highly synchronous calving. Early bred females, despite their longer gestation, still calved early, 18-20 d before the late bred females. This phenomenon is emphasized by the work of Mysterud et al., (2009) who found gestation length to increase with maternal age; i.e. mature, heavier reindeer bred earlier and had longer gestation lengths. If gestation is being lengthened as a result of nutritional constraints on fetal growth during late pregnancy, then multiparous, well-conditioned females are the last group one would expect to extend gestation.

What is being described here appears to be a seasonal affect on gestation length (Berger 1992, Garcia et al. 2006, Holand et al. 2006, Mysterud et al. 2009), the earlier in the season a female is bred, the longer her gestation. These disparate gestation lengths produce calves of equivalent weight and viability (Shipka et al. 2007b), and are independent of nutrition. The possibility that gestation adjustment may be occurring early in pregnancy is worth investigating.

\section{Embryonic diapause}

Embryonic diapause or delayed implantation has been described as the 'uncoupling of mating and fertilization from birth' (Lopes et al. 2004) and is a very rare phenomenon in cervids. It has only been documented unequivocally in the roe deer (Short \& Hay 1966) and suggested in Père David's deer (Brinklow \& Loudon 1993). Key prerequisites for delayed implantation are an uncharacteristically long gestation length (as a function of maternal body weight) and a mechanism to prevent luteolysis during the period of blastocyst delay. Roe deer are monestrus, undergoing pseudopregnancy in the absence of conception (Short \& Hay 1966, Aitken 1974, Lambert et al. 2001), have the longest gestation length among Cervidae ( $>285$ d) (Brinklow \& Loudon 1993) and are obligate delayed implanters (Short \& Hay 1966). Père David's deer also have a long gestation (283-84 d) (Brinklow \& Loudon 1993). Although Père David's deer are polyestrus, the first cycle of the season can range from $45-60 \mathrm{~d}$ in length (Curlewis et al. 1988) and Brinklow and Loudon (1993) have speculated that the extended cycles may be comparable to 'pseudopregnancy'. They concluded that Père David's deer most likely have a brief obligate delay of implantation or slower post implantation development compared to other cervids. 
Reindeer share none of the characteristics common to roe deer and Père David's deer. Reindeer breed in the fall, are polyestrus with regular cycle lengths during the breeding season (Shipka et al. 2007a), and have a gestation length compatible with maternal body size. In fact, reindeer gestation length is a bit short when viewed as a function of $\log _{10}$ maternal body weight (Brinklow \& Loudon 1993). There is nothing to suggest an obligate period of delayed implantation in this species. However, before dismissing embryonic diapause as a potential mechanism in gestation plasticity, it is worth considering the physiology of this poorly understood strategy (Renfree \& Shaw 2000; Lopes et al. 2004). Facultative diapause is a category distinct from obligate diapause and is best known as 'lactational diapause' in rodents and marsupials (Renfree \& Shaw 2000; Lopes et al. 2004). Facultative diapause is very sensitive to environmental and maternal cues and can be experimentally induced. While we do not intend to suggest that reindeer employ delayed implantation, the physiological mechanisms for temporarily suspending or slowing blastocyst development exist and have evolved several times in wide ranging, unrelated taxa. The speculation that many mammalian species, including humans, may be capable of expressing diapause under appropriate conditions has been suggested (Tarin \& Cano 1999).

\section{Melatonin}

Melatonin, a seasonal hormone, is produced in the brain by the pineal gland. Its synthesis and release occurs in response to darkness and it is suppressed by light (Lincoln 1998). Thus, the duration of circadian melatonin secretion becomes a signal for photoperiod, while the continually changing ratio of light to dark encodes annual events. If there is a seasonal affect on gestation length, melatonin must be involved, at the very least to signal the advancing season. Melatonin, however, is much more than a time keeper. Among its many attributes melatonin is an effective antioxidant, scavenging free radicals directly and up-regulating other antioxidant enzymes. The antioxidant properties of melatonin have a beneficial effect on embryonic development when added to culture medium for buffalo (Manjunatha et al. 2009) and sheep (Abecia et al. 2008). Melatonin also has strong antiapoptotic signaling functions, and it can pass readily through cell membranes conferring both receptor independent and receptor mediated effects (Pandi-Perumal et al. 2006). Melatonin and melatonin receptors have been identified in several reproductive organs in a variety of species including the granulosa cells of developing follicles and luteal cells in a diverse range of mammals (see reviews; Pandi-Perumal et al. 2006, Tamura et al. 2009). While the studies investigating the role of melatonin on folliculogenesis, progesterone production and early pregnancy are equivocal, significant findings are being described, both in vitro and in vivo. In a goat model, exogenous melatonin resulted in more follicular waves, increased the rate of cleaved oocytes, advanced the timing of embryo development and enhanced blastocyst output (Berlinguer et al. 2009). Suffolk ewes treated with melatonin have a greater number of large follicles and increased ovulation rate (Noel et al. 1999). Melatonin may also be acting indirectly through enhanced follicle production or on the $\mathrm{CL}$. resulting in increased progesterone output. A number of studies have documented enhanced progesterone secretion following melatonin treatment (Wallace et al. 1988; Durotoye et al. 1997; Abecia et al. 2002; Tamura et al. 2009). During the peak breeding season in sheep (shortening days ) LH concentrations are higher and the LH surge advanced by approximately $3 \mathrm{~h}$ when compared to similar events near the end of the season (lengthening days), and frozen-thawed embryos have a greater viability when collected during peak breeding season (Mitchell et al. 2002) 


\section{Progesterone}

During the first 6 wk post conception, reindeer bred late in the season had significantly higher peripheral progesterone concentrations than reindeer bred early in the season (Rowell \& Shipka 2009). The sample size in this study was small and data are merely suggestive. But considering the fundamental importance of progesterone in early pregnancy, any relationship between season and progesterone secretion should not be overlooked. The role of progesterone concentration in the establishment of early pregnancy has been recognized for decades. Early studies, using strategic progesterone supplementation, documented positive effects on embryo development and increased embryo survival in ewes (Kleemann et al. 1994) and cattle (Garrett et al. 1988). Cattle supplemented with progesterone between 5-9 d post-ovulation demonstrated a fourfold increase in trophoblast length and a sixfold increase in uterine concentrations of IFN- $\tau$ (Mann et al. 2006). Progesterone concentration also has the ability to alter concentrations of ions, amino acids and energy substrates in the oviduct and uterine fluid (Hugentobler et al. 2010). Progesterone plays a complex and pivotal role in early embryonic survival and the establishment of pregnancy (see reviews; Spencer et al. 2008, Bazer et al. 2009). If advancing season enhances progesterone production during the early post-conception period, it is worthwhile considering progesterone's potential to enhance early embryonic development in reindeer.

\section{Conclusions}

The immediate significance of a mean 8-10 d difference in gestation length lies in understanding the physiological mechanism(s) involved in the process, especially if these are occurring during the early post-conception period. If the advancing breeding season is altering events as subtle as the pattern of follicle wave emergence or the timing of ovulation relative to luteolysis, this could impact implementation of reproductive management strategies involving estrous synchronization and bull introduction, especially in extensive reindeer ranching situations. It is important to know if blastocyst development is enhanced, or survival of frozen thawed embryos improved, later in the season when designing protocols for artificial insemination.

We need to understand the magnitude of the variability in gestation length and potential physiological mechanisms that are being engaged. Most studies have only described this variability within the framework of a normal breeding season, i.e. approximately 30-60 d. Questions such as 'how much can gestation be shortened without compromising calf growth and birth weight' and 'what benefit, if any, is conferred by extending gestation' must be asked and tested in order to improve the management capability of individuals involved in reindeer production.

\section{Acknowledgements}

The authors extend gratitude and acknowledge the considerable help provided to our program by the staff of the Reindeer Research Program, a part of the Alaska Agricultural and Forestry Experiment Station, and by the staff of the Robert G White Large Animal Research Station, a part of the Institute of Arctic Biology at the University of Alaska Fairbanks. Research by the authors cited in this paper was funded by the United States Department of Agriculture. Agricultural Forestry and Experiment Station publication 2010-002. 


\section{References}

Abecia JA, Forcada F, Casao A \& Palacin I 2008 Effect of exogenous melatonin on the ovary, the embryo and the establishment of pregnancy in sheep. Animal 2, 399-404.

Abecia JA, Forcada F \& Zuniga O 2002 Effect of melatonin on secretion of progesterone in sheep and on the development of ovine embryos in vitro. Veterinary Research Communications 26 151-158.

Aitken RJ 1974 Delayed implantation in roe deer (Capreolus capreolus), lournal of Reproduction \& Fertility 39 225-233.

Asher GW 2007 Reproductive cycles in female cervids. In Large Animal Theriogenology 2, pp 921-936. Eds RS Youngquist \& WR Threlfall. St Louis: Saunders, Elsevier.

Asher, GW 2006 Gestation length in red deer: genetically determined or environmentally controlled? In Reproduction in Domestic Ruminants VI pp 255-260 Eds Jl Juengel, JF Murray \& MF Smith. United Kingdom: Nottingham University Press.

Asher GW, Mulley RC, O'Neill KT, Scott IC, Jopson NB \& Littlejohn RP 2005a Influence of level of nutrition during late pregnancy on reproductive productivity of red deerl. Adult and primiparous hinds gestating red deer calves. Animal Reproduction Science $\mathbf{8 6}$ 261-283.

Asher GW, Scott IC, O'Neill KT \& Littlejohn RP 2005b Influence of level of nutrition during late pregnancy on reproductive productivity of red deer: (2) Adult hinds gestating wapiti $x$ red deer crossbred calves. Animal Reproduction Science $\mathbf{8 6}$ 285-296.

Bazer FW, Spencer TE, Johnson GA \& Burghardt RC 2009 Comparative aspects of implantation. Reproduction 138 195-209.

Berger J 1992. Facilitation of reproductive synchrony by gestation adjustment in gregarious mammals: a new hypothesis. Ecology 73 323-329.

Bergerud AT 1975 The reproductive season of Newfoundland caribou. Canadian loumal of Zoology 53 1213-1221.

Berlinguer F, Leoni GG, Spezzigu A, Madeddu M, Satta V, Bebbere D, Contreras-Solis I, Gonzalez-Bulnes A \& Naitana S 2009 Exogenous melatonin positively influences follicular dynamics, oocyte developmental competence and blastocyst output in a goat model. lournal of Pineal Research 46 383-391.

Blake JE, Rowell JE \& Shipka MP 2007 Reindeer Reproductive Management. In Large Animal Theriogenology, pp. 970-974. Eds RS Youngquist \& WR Threlfall. St Louis, Ml: Saunders, Elsevier.

Blake JE, Rowell JE \& Suttie JM 1998 Characteristics of first-antler growth in reindeer and their association with seasonal fluctuations in steriod and insulin-like growth factor 1 levels. Canadian lournal of Zoology 76 2096-2102.

Blom AK, Sjaastad OV \& Jacobsen E 1983 Plasma levels of progesterone and oestradiol-17B in reindeer (Rangifer tarandus tarandus) during pregnancy. Acta Veterinaria Scandinavica 24 287-294.
Bowyer RT, Van Ballenberghe V \& Kie JG 1998 Timing and synchrony of parturition in Alaskan moose: Long. term versus proximal effects of climate: Journal of Mammalogy $791332-1344$.

Brinklow BR \& Loudon ASI 1993 Gestation period in the Père David`s Deer: evidence for embryonic diapause or delayed development. Reproduction Fertility and Development 5 567-575.

Bubenik GA, Schams D, White RG, Rowell JE, Blake IE \& Bartos L 1997 Seasonal levels of reproductive hormones and their relationship to the antler cycle of male and female reindeer. Comparative Biochemistry and Physiology 116B 269-277.

Byers IA \& Hogg IT 1995 Environmental effects on prenatal growth rate in pronghorn and bighorn: further evidence for energy constraint on sex-biased maternal energy expenditure. Behavioral Ecology 6 451-457.

Cronin MA, Patton JC, Balmysheva N \& MacNeil MD 2003 Genetic variation in caribou and reindeer (Rangifer tarandus). Animal Genetics 34 33-41.

Curlewis JD, Loudon ASI \& Coleman APM 1988 Oestrous cycles and the breeding season of the Père Davids's deer hind (Elaphurus davidianus). Journal of Reproduction and Fertility 82 119-126.

Davis GH, Dodds KG, Moore GH \& Bruce GD 1997 Seasonal effects on gestation length and birth weight in alpacas. Animal Reproduction Science 46 297-303.

Diamond J 1999 Zebras, unhappy marriages and the Anna Kerenina principle. In Guns, Germs, and Steel; the Fate of Human Socielies. Pp 157-175. New York: WW Norton and Company.

Doft HM \& Utsi, MNP 1973 Artificial insemination of reindeer. Journal of Zoology (London) 170 505-508.

Durotoye LA, Webley GE \& Rodway RG 1997 Stimulation of the production of progesterone by the corpus luteum of the ewe by the perfusion of melatonin in vivo and by treatment of granulosa cells with melatonin in vitro. Research in Veterinary Science 62 87-91.

Elias E, Degen AA \& Kam M 1991 Effect of conception date on length of gestation in the dromedary camel (Camelus dromedarius) in the Negev Desert. Animal Reproduction Science 25 173-177.

Eloranta E \& Nieminen M 1986 The effects of maternal age and body weight on reindeer calf birth-weight and survival. Rangifer 1105.

Eloranta E \& Nieminen M 1988 Calving and maternal body weight change in the reindeer. Rangifer 2(special issuel 64-65.

Fauchald P, Tveraa T, Henaug C \& Yoccoz NG 2004 Adaptive regulation of body reserves in reindeer, Rangifer tarandus: A feeding experiment. Oikos 107 583-591.

Flood PF, Tyler NJC, Read EK, Rodway MJ \& Chedrese P) 2005 Ovarian and placental production of progesterone and oestradiol during pregnancy in reindeer. Animal Reproduction Science 85 147-162.

Flydal K \& Reimers E 2002 Relationship between calving time and physical condition in three wild reindeer (Rangifer tarandus) populations in southern Norway. 
Wildlife Biology 8 145-152.

Garcia AJ, Landete-Castillejos T, Carrion D, GasparLopez E \& Gallego L 2006 Compensatory extension of gestation length with advance of conception in red deer (Cervus elaphus). Journal of Expermental Biology 305A, 55-61.

Garrett JE, Geisert RD, Zavy MT \& Morgan GL 1988 Evidence for maternal regulation of early conceptus growth and development in beef cattle. loumal of Reproduction and Fertility $\mathbf{8 4}$ 437-466.

Goss RJ 1983 Deer Antlers. New York: Academic Press.

Holand O, Mysterud A, Roed KH, Coulson T, Gjostein H, Weladji RB \& Nieminen M 2006 Adaptive adjustment of offspring sex ratio and maternal reproductive effort in an iteroparous mammal. Proceedings of the Royal Society B $273 \quad 293-299$.

Howell, CE \& Rollins, WC 1951 Environmental sources of variation in gestation length of the horse. Journal of Animal Science $10789-796$.

Hugentobler SA, Sreenan IM, Humpherson PG, Leese HJ, Diskin MG \& Morris DG 2010 Effects of changes in the concentration of systemic progesterone on ions, amino acids and energy substrates in cattle oviduct and uterine fluid and blood. Reproduction Fertility and Development 22 684-694.

Kleemann DO, Walker SK \& Seamark RF 1994 Enhanced fetal growth in sheep administered progesterone during the first three days of pregnancy, Journal of Reproduction and Fertility $102 \quad 411-417$.

Klein DR 1980 Conflicts between domestic reindeer and their wild counterparts: A review of Eurasian and North American experience, Arctic 33 739-756.

Lambert RT, Ashworth CJ, Beattie L, Gebbie FE, Hutchinson JSM, Kyle DJ \& Racey PA 2001 Temporal changes in reproductive hormones and conceptusendometrial interactions during embryonic diapause and reactivation of the blastocyst in European roe deer (Capreolus capreolus). Reproduction 121 863-871.

Leader-Williams N 1988 Reindeer on South Georgia: The ecology of an introduced population. pp 1-319 Great Briton: Cambridge University Press.

Lenvik D, Ebsen B \& Fjellheim A 1988 Relationship between the weight of reindeer calves in autumn and their mother's age and weight in the previous spring. Rangifer 8 20-24.

Lincoln GA 1998 Photoperiod-melatonin relay in deer. Acta Veterinaria Hungarica 46 341-356.

Lopes FL, Desmarais JA \& Murphy BD 2004 Embryonic diapause and its regulation. Reproduction 128669 678.

Manjunatha BM, Devaraj M, Gupta PSP, Ravindra JP \& Nandi S 2009 Effect of taurine and melatonin in the culture medium on buffalo in vitro embryo development. Reproduction in Domestic Animals 44 12-16.

Mann GE, Fray MD \& Lamming GE 2006 Effects of time of progesterone supplementation on embryo development and interferon-t production in the cow. The Veterinary lournal 171 500-503.

McEwan EH \& Whitehead PE 1972 Reproduction in female reindeer and caribou. Canadian lournal of Zoology 50 43-46.

Mitchell LM, Dingwall WS, Mylne MJA, Hunton J, Matthews K, Gebbie FE, McCallum GJ \& McEvoy TG 2002 Season affects characteristics of the pre-ovulatory L.H surge and embryo viability in superovulated ewes. Animal Reproduction Science 74 163-174.

Moore GH \& Littlejohn RP 1989 Hybridisation of farmed wapiti (Cervus elaphus manatobensis) and red deer (Cervus elaphus). New Zealand Journal of Zoology 16 191-198.

Mysterud A, Roed KH, Holand O, Yoccoz NG \& Nieminen M 2009 Age-related gestation length adjustment in a large iteroparous mammal at northern latitude. lournal of Animal Ecology 79 1002-1006.

Noel B, Mandiki SM \& Paquay R 1999 Terminal fallicular growth, ovulation rate and hormonal secretion after melatonin pretreatment prior to FGA-PMSG synchronisation in Suffolk ewes at the onset of the breeding season. Small Ruminant Research 32269 . 277.

Norman HD, Wright JR, Kuhn MT, Hubbard SM, Cole IB \& VanRaden PM 2009 Genetic and environmental factors that affect gestation length in dairy cattle. lournal of Dairy Science 92 2259-2269.

Pandi-Perumal SR, Srinivasan V, Maestroni GJM, Cardinali DP, Poeggeler B \& Hardeland R 2006 Melatonin Nature's most versatile biological signal? FEBS 273 2813-2838.

Rachlow JL \& Bowyer RT 1991 Interannual variation in timing and synchrony of parturition in Dall's sheep. lournal of Mammalogy 72 487-492.

Reimers E 2002 Calving time and foetus growth among wild reindeer in Norway. Rangifer 22 61-66.

Renfree MB \& Shaw G 2000 Diapause. Annual Review of Physiology 62 353-375.

Rognmo A, Markussen KA, Jacobsen E, Grav HI \& Blix AS 1983 The effects of improved nutrition in pregnant reindeer on milk quality, calf birth weight, growth and mortality. Rangifer 3 10-18.

Roine K 1974 Studies on reproduction in female reindeer. Helsinki: Helsingin Liikekirjapaino. Helsinki College of Veterinary Medicine.

Ronnegard L, Forslund P \& Danell O 2002 Lifetime patterns in adult female mass, reproduction, and offspring mass in semidomestic reindeer (Rangifer tarandus tarandus). Canadian lournal of Zoology $\mathbf{8 0}$ 2047-2055.

Ropstad E, Veiberg V, Sakkinen H, Dahl E, Kindahl H, Holand O, Beckers JF \& Eloranta E 2005 Endocrinology of pregnancy and early pregnancy detection by reproductive hormones in reindeer (Rangifer tarandus tarandus). Theriogenology 63 1775-1788.

Rowell JE \& Shipka MP 2009 Variation in gestation length among captive reindeer (Rangifer tarandus tarandus). Theriogenology 72 190-197.

Sakkinen H, Timisjarvi I \& Puukka M 1999 Nutritioninduced changes in blood chemical parameters of pregnant reindeer hinds (Rangifer tarandus tarandus). 
Small Ruminant Research 32211.

Schwartz CC \& Hundertmark KJ 1993 Reproductive characteristics of Alaskan moose, Journal of Wildlife Management 57 454-468.

Scott IC, Asher GW, Archer JA \& Littlejohn RP 2008 The effect of conception date on gestation length of red deer (Cervus elaphus). Anim Reprod Sci 109 206-217.

Shipka MP \& Rowell JE 2006 Gestation length in Alaskan reindeer. Journal of Animal Science $\mathbf{8 4}$ (Suppl 1).

Shipka MP, Rowell JE \& Ford SP 2002 Reindeer bull introduction affects the onset of the breeding season. Animal Reproduction Science 72 27-35.

Shipka MP, Rowell JE \& Sousa MC 2007a Steroid hormone secretion during the ovulatory cycle and pregnancy in farmed Alaskan reindeer. Journal of Animal Science 85 944-951

Shipka MP, Rowell JE \& Young A J 2007b Relationship of Dam's body weight, milk components, and milk energy density to reindeer calf growth rate. Journal of Animal Science 58 126-130.

Short RV \& Hay MF 1966 Delayed implantation in the Roe deer (Capreolus capreolus) In Comparative Biology of Reproduction in Mammals, pp. 173-194. Ed IW Rowlands. New York: Academic Press.

Skogland T 1984 The effects of food and maternal conditions on fetal growth and size in wild reindeer. Rangifer 4 39-46.
Skogland T 1990 Density dependence in a fluctuating wild reindeer herd; maternal vs offspring effects. Oecologia 84 442-450.

Spencer TE, Olivier S \& Eckhard W 2008 Genes involved in conceptus-endometrial interactions in ruminants: insights from reductionism and thoughts on holistic approaches. Reproduction 135 165-179.

Tamura H, Nakamura Y, Korkmaz A, Manchester LC, Tan D-X, Sugino N \& Reiter RJ 2009 Melatonin and the ovary: physiological and pathophysiological implications. Fertility and Sterility 92 328-343.

Tarin JI \& Cano A 1999 Do human concepti have the potential to enter into diapause? Human Reproduction 14 2434-2436.

Tveraa T, Fauchald P, Henaug C \& Yoccoz NG 2003 An examination of a compensatory relationship between food limitation and predation in semi-domestic reindeer. Oecologia 137 370-376.

Wallace JM, Robinson JI, Wigzell S \& Aitken RP 1988 Effect of melatonin on the peripheral concentrations of $\mathrm{LH}$ and progesterone after oestrus and on conception rate in ewes. Journal of Endocrinology 119 523-530. 